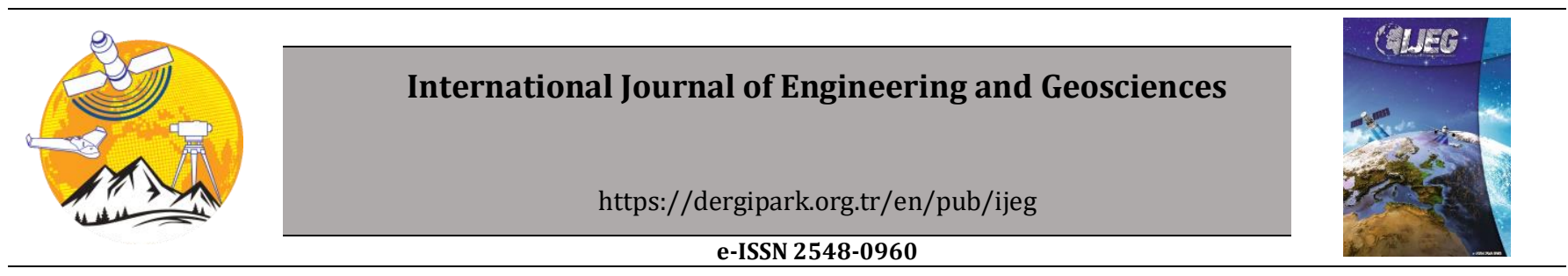

\title{
3D city model for monitoring flash flood risks in Salalah, Oman
}

\author{
Khalid Al Kalbani*1ㅁ, Alias Abdul Rahman ${ }^{1}$ (D) \\ 1Universiti Teknologi Malaysia, 3D GIS Research Lab, Faculty of Built Environment and Surveying, Johor Bahru, Malaysia
}

\section{Keywords}

Flood risk management

3D city model

CityGML

\begin{abstract}
This paper investigates the issues and challenges in using a 3D city model for monitoring flash flood risks in Salalah (Oman) designed using the City Geography Markup Language (CityGML) standards version 2.0. The investigation was made based on the fact that 2D and 2.5D GIS solutions cannot analyse flood complex problems inside the urban area. Hence, the study sought to reduce time and effort for the decision-makers by proposing a 3D city model for flood risk management. The study used geospatial tools and databases such as ArcGIS, Watershed Modelling System (WMS), FME, PostgreSQL-PostGIS, and 3D City Database (3DCityDB) to generate the 3D model and to test the capability of establishing a unified geospatial data structure including the 3D city objects, hydrological data, and geological data. The findings showed the importance of addressing flood risks data and arranging it in the 3D geodatabase. It was also revealed that establishing a 3D city model based on the CityGML standard requires homogenised definitions and standards for city objects (surface and subsurface) as well as hydrological data.
\end{abstract}

\section{INTRODUCTION}

Oman has coasts with a length of 3165 kilometres that facing towards the Indian Ocean, where tropical storms occur. Therefore, it experiences frequent climatic events such as tropical depression and cyclone (AlKalbani, 2011; Dube et al., 2020). In addition to that, the low parts of the coastal areas can be exposed to coastal floods caused by high waves that come along with the climactic event. These climatic events affect human lives and cause damage to city infrastructure, which costs millions of dollars. Salalah is one of the south Omani cities that has faced several climatic events such as cyclone Mekunu in 2018 and tropical depression from 27 May to 1 June 2020, as shown in Fig. 1.

The impact of these events has led to the importance of evaluating Salalah city infrastructure by using the 3D geospatial data approach to test the extent to which the Salalah city infrastructure matches with the hydrological system in that area. This study, thus, investigates the issues and challenges of implementing a 3D city model to monitor, evaluate and manage these dangers by developing a small-scale 3D city model using CityGML standard version 2.0 .

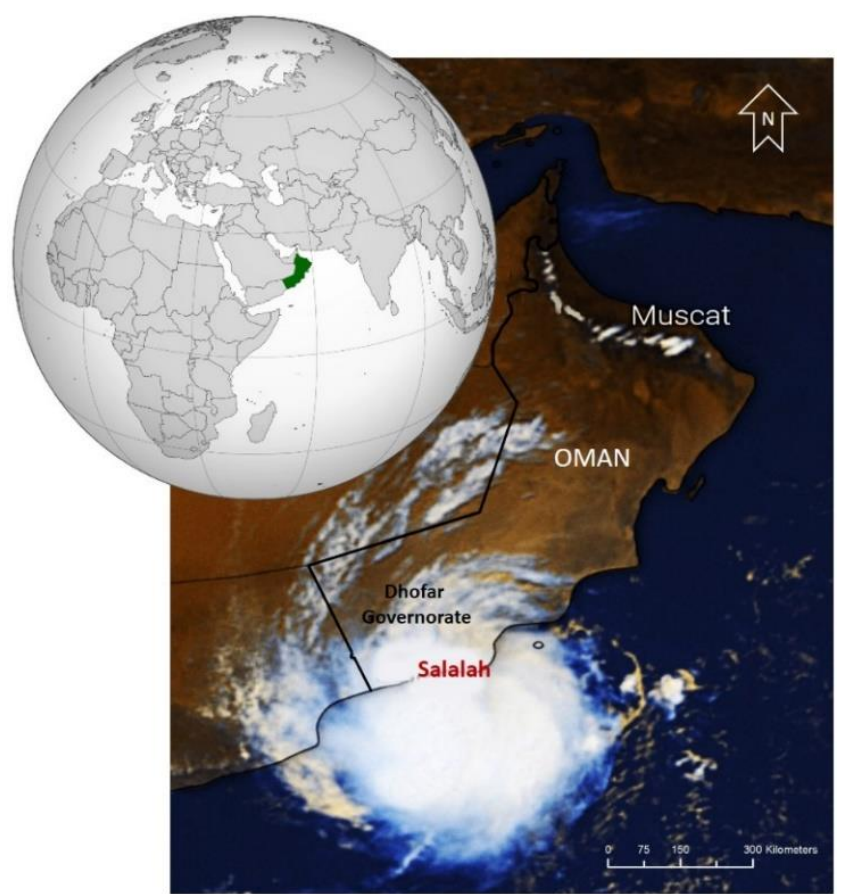

Figure 1. The tropical depression, 30 May 2020 
Monitoring and assessing flash floods and managing mitigation measures is a complex project that requires great effort and a relatively long period of time. The study seeks to reduce time and effort by employing a 3D city model, which mainly depends on the design of the 3D city model databases to manage the influence of the flood risk on the city infrastructure (surface and sub-surfaces spatial objects). Bee et al. (2008), Ruíz (2015) and Tymkow et al. (2016) demonstrated that a mechanism could be established to deal with flood risk data by linking geospatial data and identifying effective models, analysing appropriate simulation, estimation techniques, and designing a flood intensity scale. On the other hand, The Bureau for Crisis Prevention and Recovery (BCPR) in its 2004 international report indicated that more efforts should be made to collect disaster-related data. Also, it pointed out in its recommendations, the need to support the national risk management to produce the information needed for decision-making at a national level (UNDP, 2004).

Nowadays, the infrastructure such as multi-floor buildings and underground utilities, indoor and outdoor spatial objects in the urban areas is complicated as it requires using $3 \mathrm{D}$ geodata sets and $3 \mathrm{D}$ geospatial platforms with high performance. Additionally, employing the current geospatial solutions may not be useful to analyse and visualise complex problems, so there is an urgent need to develop 3D city model based on interoperability solutions (Biljecki et al., 2015b; Stoter et al., 2014, 2010). 3D geospatial platforms, 3D database and their related applications are considered as good initiatives to represent the 3D spatial objects and entire cities. The capability of these geospatial technologies offer some solutions in analysing complex data structure issues (Abdul Rahman et al., 2019; Siew and Kumar, 2019; Yao et al., 2018). Hence, efforts to make the 3D city model successful for flood risk management requires a homogenous and stable environment for all models and standards in terms of hydrology, meteorology, geomorphology, geology, and hydrogeology.

A number of countries around the world have applied the GIS for flood risk management, while other countries are working toward 3D GIS by using their standard, data format and database (Al-Kalbani, 2011; Ruíz, 2015). At this point, the 3D geospatial institutions and researchers have made an effort to develop a framework for flood modelling based on the use of OGC CityGML standard, CityJSON and others. Nevertheless, the pre-implementation has exposed several issues and challenges that need to be addressed during data processing, data integration, data modelling, data converting, and data visualising (Al Kalbani and Abdul Rahman, 2019; Kumar et al., 2018; Zlatanova et al., 2014). Part of the challenges is related to DEM sources efficiency in 3D flood modelling and complex hydraulic simulation. In this context, Bakuła et al. (2016) and Li and Wong (2010) investigated how hydraulic modelling and application can be influenced by the source of different elevation data. Meanwhile, Muhadi et al. ( 2020) discussed the use of Digital Elevation Model (DEM) extruded from LiDAR for flood applications.
Establishing a flood risk database within the 3D city model is a complex task at the national level. On the one hand, dealing with 3D city model requires new solutions to integrate the data structure for both the surface and subsurface spatial objects (Al Kalbani and Abdul Rahman, 2019). This is because most of the 3D geospatial initiatives focus on surface spatial objects data structure with less interest to model the subsurface spatial objects. On the other hand, there is a need to find an approach that bridges between different available 3D geospatial standards in terms of geometric and semantics information to supports the interoperability between Database Management Systems (DBMS), services, and stakeholders (Stoter et al., 2010).

This paper is arranged in nine sections, where Section 2 discusses the study area. Then, Section 3 reviews the CityGML standard. Section 4 reviews the current state of Oman geospatial data and Spatial Data Infrastructure (SDI), followed by the data and methods in Section 5. The Section 6 includes the discussion and outcomes of the study. Section 7 highlights the issues and challenges. The benefit of implementing a 3D city model for flood risk management is summarised in Section 8, and finally, Section 9 concludes the paper.

\section{STUDY AREA}

Salalah is one of the main cities in the Dhofar Governorate (southwest of the Sultanate of Oman) (Zerboni et al., 2020). The population of the governorate has reached 416,458 in December 2020 (NCSI, 2020), distributed between the coastal plain and mountainous and desert areas. The urban area in Salalah is spread on a narrow coastal plain, located between mountains, that are more than 1000 meters high (see Fig. 2), and a coastal line with a number of wadis and alluvial fans passing throughout the area.

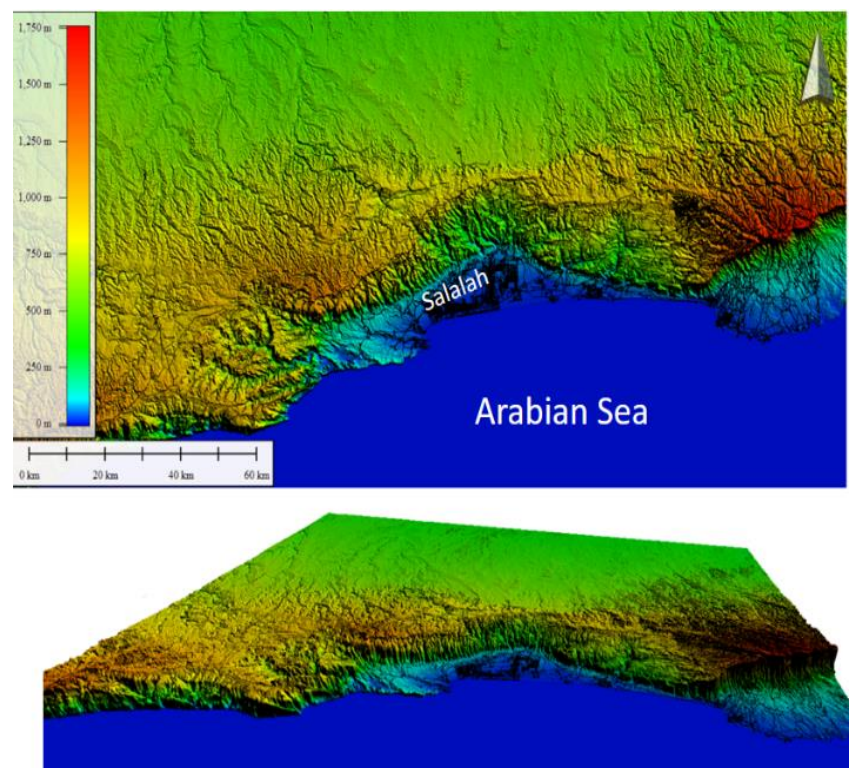

Figure 2. The digital elevation model (DEM) of Salalah

The coastal plain can reach $13 \mathrm{~km}$ in its maximum width. The mountain range in this area was formed by tectonic activity and uplift movement (Zerboni et al., 2020). Most of the rocky structure scattered in this region is dominated by solid limestone. 
Dhofar is considered a semi-arid area with approximately 100-400 $\mathrm{mm}$ of rainfall per year (Zerboni et al., 2020). This area also has a monsoon from July to August, in which the weather becomes cloudy with little rain. This area can also be affected by cyclones and tropical depressions. One of the clime events Dhofar had experienced is the tropical depression (27 May to 1 June 2020) which caused heavy rains so much causing some of the Dhofar districts to receive more than $1000 \mathrm{~mm}$ of rains in 5 days. Salalah (study area) received $531 \mathrm{~mm}$, causing flash floods and destroying some city infrastructure (Mrmwroman, 2020).

Rapid development in Salalah plays a role in the occurrence of natural phenomena such as floods. The accelerated pressure on urban spatial holdings contributed to the exploitation of flood-prone areas, and most exploitation was not accompanied by providing the infrastructure of water drainage (Al-Kalbani, 2011). The Crisis and Recovery Office has indicated in its global report to UNDP 2004 that "it does not necessarily mean that the urban transformation increases flood risk and can actually reduce it if it is well managed" (UNDP, 2004). However, the damage caused by floods cannot always be the main natural factor for exacerbating events. Instead, it is often the human factor that provides the right environment for these risks to develop into disasters.

The high cost for constructing and maintaining the flood protection infrastructure constrained the integration of flood risk measures into urban planning efforts effectively. In fact, establishing flood risk infrastructure at the government level can be affected by two elements, namely the economic feasibility and practical feasibility. Often, the economic factor is the dominant factor in addition to the amount of available budget (Al-Kalbani, 2011). In all scenarios, when planning deviates from the inclusion of flood risk as a priority, this uncontrolled planning may cause challenges in normal rainfall and make matters worse in the case of heavy rains.

\section{CityGML STANDARD}

CityGML is an open XML file format for exchanging, storing, and representing 3D objects. Its initiatives have been developed by the Special Interest Group 3D (SIG 3D). Now, it is organised by Open Geospatial Consortium (OGC). CityGML standard has been adopted as an international standard to exchange the format of 3D geospatial objects and the 3D city model based on the XML file format and the GML 3xx. Besides, CityGML version 2.0 includes 13 models to store the spatial objects and five levels of detail (LoD) (Biljecki, 2017; Biljecki et al., 2015b; Stouffs et al., 2018).

CityGML presents the most common natural and human spatial features that can be found in the cities and their surroundings by determining their geometric and semantic information (Arroyo Ohori et al., 2018; Biljecki, 2017; Biljecki et al., 2017, 2015a, 2015b; Kensek, 2014; Stoter et al., 2016). Furthermore, the structure of CityGML file format is developed based on the hierarchy structure for both geometric and semantic information. Now, there are various spatial applications for CityGML standard such as solar potential estimation, flood risk assessment and noise monitoring (Biljecki, 2017; Biljecki et al., 2015b; Preka and Doulamis, 2016; Soon et al., 2016; Yao et al., 2018).

\section{THE CURRENT STATE OF OMAN GEOSPATIAL DATA AND SDI}

Oman government established its National Spatial Data Infrastructure (NSDI) in 2014 to standardise the geospatial activities and business at the national level. Since then, the geospatial workflow of Oman NSDI and its partners (Oman GIS stakeholders) are limited to the 2D and 2.5D geospatial data (Al Kalbani et al., 2018; Das et al., 2017; NCSI, 2017a, 2017b). In fact, Oman is one of the developed countries which has a complex city infrastructure. As a result, using 2D and 2.5D geospatial data may not be efficient in analysing flood risk inside the big cities and complex structures. Hence, the decisionmakers in Omani municipalities need GIS solutions based on utilising a 3D city model.

\section{DATA AND METHODS}

\subsection{Data}

The study created a small-scale 3D city model for Salalah district using CityGML version 2.0 and spatial data collected from the related geospatial agencies in Oman (2D, 2.5D geospatial data). Satellite images (Sentinel-2) with a resolution of 10 meters for the tropical depression from 1-3 June 2020 were obtained from https://eos.com/landviewer.

\subsection{Method}

The methodology in this study is given below.

\subsubsection{Creating Surface and Subsurface Models at LoD1}

A building model was created at CityGML LoD1 by extruding the building footprint using a high value from the file attributes. LoD1 was also used to create a terrain model. Geospatial tools such as FME engine was used to generate 3D spatial objects for surface and subsurface spatial objects based on CityGML standard version 2.0 and also for exchanging the file format from one model to the other. Since the CityGML 2.0 does not fully support the subsurface spatial objects and models, the study used the CityGML generic module to develop some of these subsurface models such as geological model and pipeline networks.

\subsubsection{Creating Wadi Networks and Watershed}

The study used ArcGIS (hydrology tools) and the Watershed Modelling System (WMS) to extract wadi (stream) networks and watershed using ASTER DEM with a resolution of 30 meters. Besides, WMS applications were used to produce flood spread layers based on digital terrain data and floodwater estimative elevation values between 1 - 3 meters. 


\subsubsection{Creating A unified 3D Database}

The study carried out some experiments to investigate further the issues and challenges for constructing a unified 3D database. Related to this, databases PostgreSQL-PostGIS and 3DCityDB were used to register and store the 3D models for surface and subsurface objects in a relational database. It also, explored the data structure integration challenges between geological models, hydrological models and 3D city models.

\subsubsection{Integration Between Satellite Images and 3D City Models}

The study investigated how to integrate the benefits of satellite images and 3D city models for flood risk management. Satellite images (Sentinel-2) were analysed using change detection methods. The role of satellite images in this study is to draw a map of the flood spread in the study area by overlapping the 3D models (building and road) in the 3D city model with 2D satellite images that are classified using change detection. In addition, this step contributed to tracking and highlighting some of the flooding problems related to the failure of drainage networks along highways and inside cities.

\subsubsection{Visualising}

Since there is no professional 3D viewer to visualise both surface and subsurface spatial objects, the study used visualising tools such as FME Data Inspector, Google Earth, FZK viewer and Cesium.

\section{RESULTS AND DISCUSSION}

A small-scale 3D city model was created for most surface city spatial objects in LoD 1 (see Fig. 3). However, it faced a challenge to go higher to LoD 3 and LoD 4 due to missing rich data such as BIM/IFC. In addition, the study able to generate wadi (stream) networks and watershed using Salalah digital terrain data.

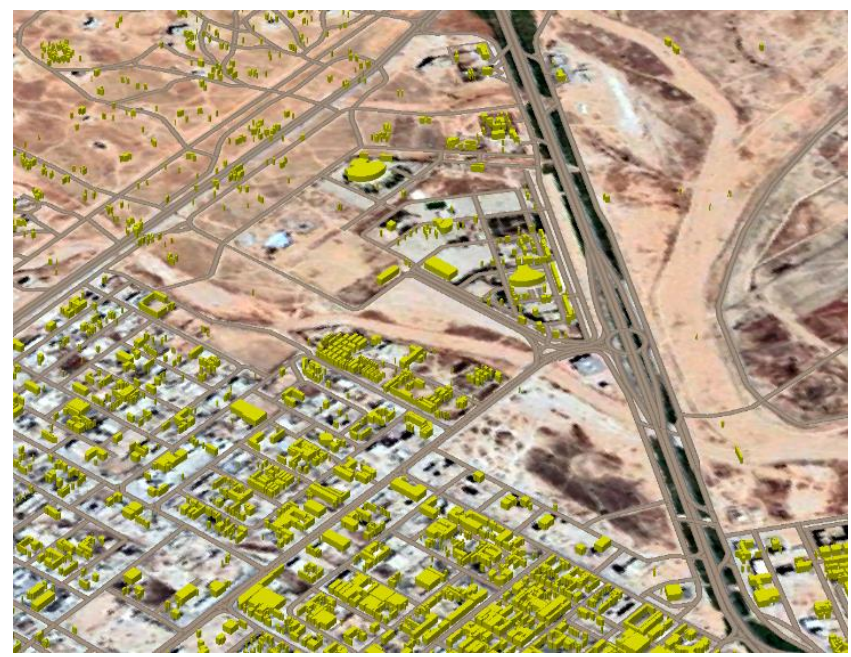

Figure 3. The small-scale 3D city model for Salalah

The real challenge in developing the 3D city model was how to create the subsurface spatial objects. This is because the CityGML version 2.0 does not provide a definition to support the subsurface objects except for the CityGML Application Domain Extension (ADE) for utility network. Thus, the study created some of the subsurface spatial objects in LoD1 using the CityGML generic module. However, there are some challenges related to semantic, geomatic and topology that need to be addressed to enhance 3D subsurface models. Other challenges are related to 3D spatial analysis and the process of creating a unified relational database for surface and subsurface spatial objects.

Since the CityGML version 2.0 does not include hydrological models and flooding simulation, this study used several applications separately and the outcomes were linked to one 3D city model. During this stage, the experiments showed that the 3D city model was able to determine the areas that might be subjected to water flooding by linking the 3D city model, terrain and flood layer exported from WMS, as shown in Fig. 4.

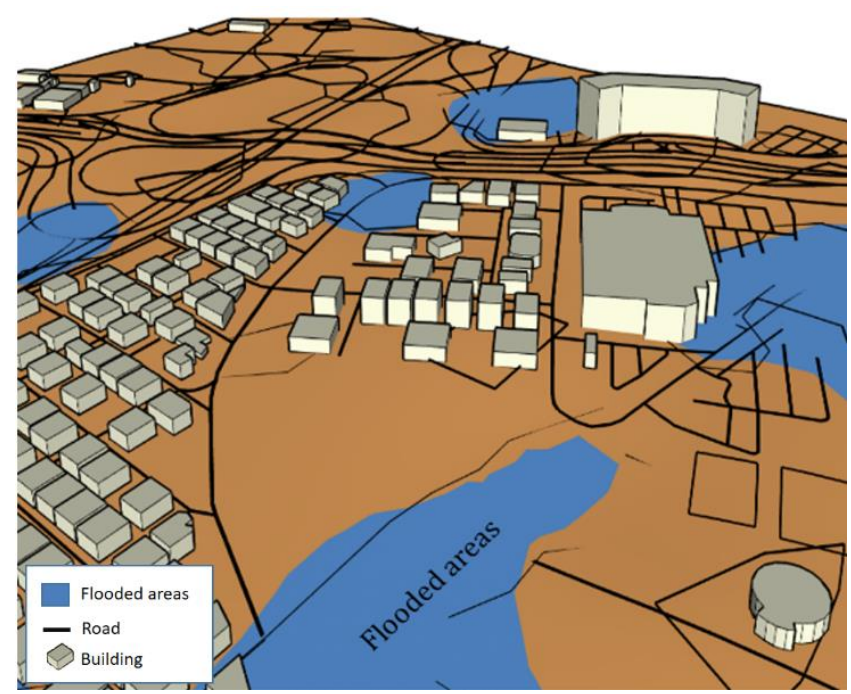

Figure 4. The areas subjected to flooding

Another advantage of managing flood data in 3D city model is providing the capability to determine the level to which floodwater can reach in each of the city buildings (see Fig. 5).

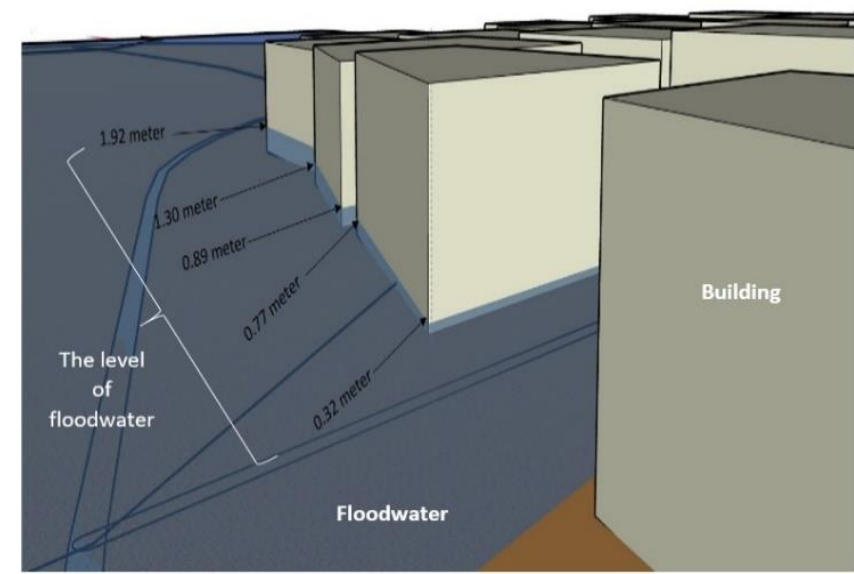

Figure 5. The level of floodwater in residential areas

Nevertheless, there is still a challenge in registering the value to which floodwater can reach automatically in 
the database for each of the building faces and edges due to the complexity of CityGML data structure in terms of systematic and geometric information.

Moreover, the experiments demonstrated that there is a possibility to integrate the analysis of satellite images using change detection methods and 3D city models to map the distribution of internal floods in residential areas and to highlight some issues in the city infrastructure (see Fig. 6).

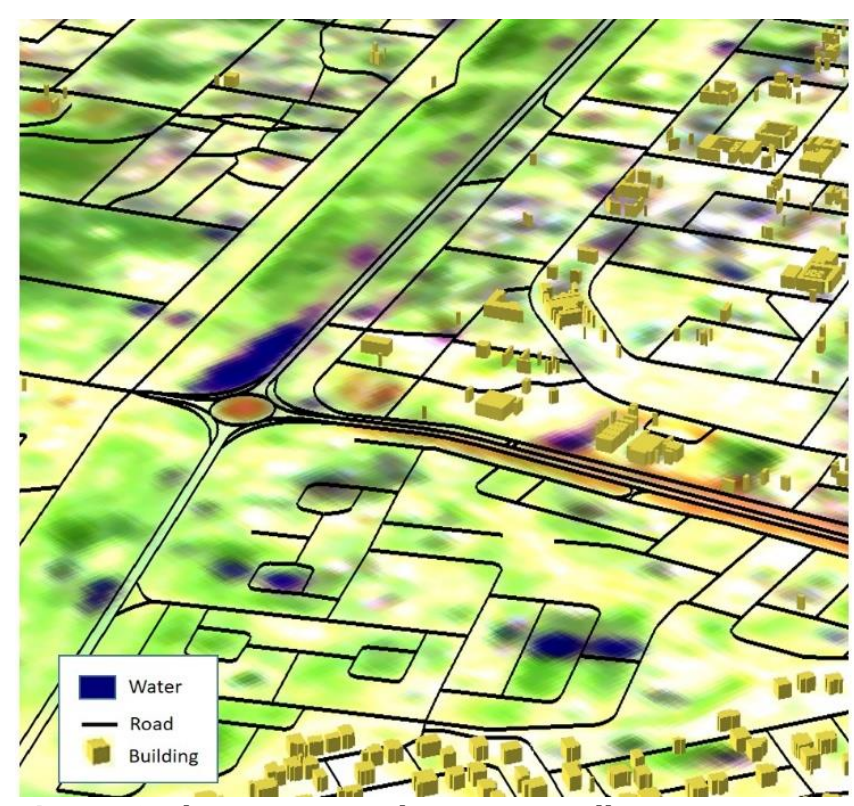

Figure 6. The integration between satellite images using the change detection method and 3D city models

Based on this approach, the results revealed that floodwater collects on the sides of highways and some modern bridges as well as residential areas. There are many reasons that can caused the phenomenon, but lack of water drainage networks, failure of drainage channels due to accumulation of impurities coming from the watershed, incompatibility of the engineering design of the drainage channels and the volume of water flow are the most important factors. Other challenges are due to the low level of the ground surface in some residential areas and weak water infiltration into the ground.

\section{ISSUES AND CHALLENGES}

The establishment of a 3D city model for flood risk monitoring based on the use of CityGML version 2 requires compatible solutions. Hence, this study was performed to address the issues and challenges listed as follows:

- Integrating the CityGML and the current mathematic hydrological models in a unified ADE, data structure and 3D geodatabase.

- Designing suitable equations to estimate the floods' peak considering Salalah environment, climate, the nature of urban patterns and characteristics of dams and their ability to drain water. Therefore, creating hydrodynamic modelling of flood flows using CityGML standard needs to determine the relation with other factors such as the surface of the wadi, slope, velocity, leakage rate to the underground, evaporation, and 3D objects resistance.
- Upgrading 3DCityDB data structure to import subsurface spatial objects.

- Developing homogenised definitions within CityGML standard to manage relationships between different subsurface spatial objects, geological models and hydrological models.

- Developing a new logarithm of hydrodynamic modelling of flood flows based on CityGML standard and $3 \mathrm{D}$ raster map (voxel).

- Calculating the water drainage that comes from the city's infrastructure, where the roofs of buildings and paved areas contribute to the gathering of rainwater in residential areas and low areas.

- Designing a mechanism to predict urban infrastructure behaviour during the flooding, where the failure of bridges, roads and drainage channels can shut down the natural paths of valleys and change the direction of their flow, causing internal flooding in residential areas.

- Integrating indoor and outdoor navigation and flood risk management.

- Updating the hydrology simulation results automatically into the databases at the level of CityGML schema(s) and LoD(s).

- Defining the water stream paths inside the city in the absence of Light Detection and Ranging (LiDAR) data, which is a restricted data in Oman and needs several official permissions.

Other challenges are related to CRS/SRID, quality of data structures, geomatics representation, the problem of semantic cording, creating the data structure in terms of schema(s) and $\operatorname{LoD}(\mathrm{s})$, integration with the DEM, the $3 \mathrm{D}$ object topology issues, flood topology issues, data retrieval, data size, data index, 3D spatial analysis, spatial operations and rendering over Cesium.

\section{THE BENEFITS OF IMPLEMENTING A 3D CITY MODEL FOR FLOOD RISK MANAGEMENT}

The expected benefits of using a 3D city model for flood risk management study are summarised as follows:

- A suitable environment for the modelling of floods and their impact on the urban areas in 3D

- The ability to test infrastructure projects before implementation on the ground

- A suitable environment for flood risk management and rescue operations

\section{CONCLUSION}

This study successfully investigated the use of a 3D city model to monitor flood risks in Salalah and determined the challenges faced during the investigation. This evidently showed that the issues and challenges are related to the efficiency of this standard for hydrological analysis and in managing surface and subsurface spatial objects in the unified data structure.

The results also demonstrated that the $3 \mathrm{D}$ geospatial data is more efficient in solving planning problems and defining the issues that may increase flood risks. This, in turn, helps to understand and assess the 
nature of risks, and thus design a clear vision to manage rescue efforts. This research is still a work-in-progress and the authors believe that the initial outcomes of this paper can highlight the importance of including 3D geospatial solutions for flood risk management in Oman. In the future, based on the outcomes, we would like to examine the performance of the JavaScript Object Notation (JSON) and CityJSON data structure as alternative solutions to create a flood spatial data structure in the 3D city model.

\section{ACKNOWLEDGEMENT}

The authors would like to acknowledge the Ministry of Higher Education, Research, and Innovation (MoHERI) of the Sultanate of Oman for supporting the main project (3D SDI). The research leading to these results has received funding from MoHERI under the GRG program. Funding Agreement No: MoHERI/GRG/INT.S/09/2020.

\section{Author contributions}

Khalid Al kalbani: Conceptualization, Methodology, Software, Data curation, Writing-Original draft preparation, Validation, and Visualization. Alias Abdul Rahman: Conceptualization, Methodology, Reviewing and Editing.

\section{Conflicts of interest}

The authors declare no conflicts of interest.

\section{REFERENCES}

Abdul Rahman, A., Rashidan, H., Musliman, I.A., Buyuksalih, G., Bayburt, S., Baskaraca, P., 2019. 3D Geospatial Database Schema for Istanbul 3D City Model. ISPRS - Int. Arch. Photogramm. Remote Sens. Spat. Inf. Sci. XLII-4/W16, 11-16. https://doi.org/10.5194/isprs-archives-XLII-4-W1611-2019

Al Kalbani, K., Abdul Rahman, A., 2019. Integration Between Surface and Subsurface Spatial Objects for Developing Oman 3D SDI Based on the CityGML Standard. Int. Arch. Photogramm. Remote Sens. Spat. Inf. Sci. XLII-4/W16, 79-84. https://doi.org/10.5194/isprs-archives-XLII-4-W1679-2019

Al Kalbani, K., Abdul Rahman, A., Al Awadhi, T., Alshannaq, F., 2018. Development Of A Framework for Implementing 3D Spatial Data Infrastructure In Oman - Issues And Challenges. ISPRS - Int. Arch. Photogramm. Remote Sens. Spat. Inf. Sci. XLII-4/W9, 243-246. https://doi.org/10.5194/isprs-archivesXLII-4-W9-243-2018

Al-Kalbani, K., 2011. Monitoring and Assessing Flood Risks \& Maintaining the Procedures to Limit their Danger using Geographical Information Systems, Remote Sensing and Hydrological Modeling (Case Study :Al-Seeb Willayat) ". Sultan Qaboos University.

Arroyo Ohori, K., Biljecki, F., Kumar, K., Ledoux, H., Stoter, J., 2018. Modeling Cities and Landscapes in 3D with CityGML, in: Building Information Modeling. Springer
International Publishing, Cham, pp. 199-215. https://doi.org/10.1007/978-3-319-92862-3_11

Bakuła, K., StĘpnik, M., Kurczyński, Z., 2016. Influence of Elevation Data Source on 2D Hydraulic Modelling. Acta Geophys. 64, 1176-1192. https://doi.org/10.1515/acgeo-2016-0030

Bee, M., Benedetti, R., Espa, G., 2008. Spatial Models for Flood Risk Assessment. Environmetrics 19, 725-741. https://doi.org/10.1002/env.932

Biljecki, F., 2017. Level of Details in 3D City Models,Published PhD Thesis. Delft University of Technology.

https://doi.org/10.4233/uuid:f12931b7-5113-47efbfd4-688aae3be248 Uzbekistan (Hz. Osman's Mushafi). International Congress on Cultural Heritage and Tourism (ICCHT), 115-123, Bishkek, Kyrgzstan.

Biljecki, F., Ledoux, H., Stoter, J., 2017. Generating 3D City Models Without Elevation Data. Comput. Environ. Urban Syst. 64, 1-18. https://doi.org/10.1016/j.compenvurbsys.2017.01. 001

Biljecki, F., Ledoux, H., Stoter, J., 2015a. Improving the Consistency of Multi-LoD CityGML Datasets by Removing Redundancy. pp. 1-17. https://doi.org/10.1007/978-3-319-12181-9_1

Biljecki, F., Stoter, J., Ledoux, H., Zlatanova, S., Çöltekin, A., 2015b. Applications of 3D City Models: State of the Art Review. ISPRS Int. J. Geo-Information 4, 2842-2889. https://doi.org/10.3390/ijgi4042842

Das, A., Chandel, K., Narain, A., 2017. Value of Geospatial Technology in Boosting Omans Economy, in: Oman Geospatial Forum 2017. Oman National Survey Authority, Muscat, pp. 1-74.

Dube, A., Ashrit, R., Kumar, S., Mamgain, A., 2020. Improvements in Tropical Cyclone Forecasting through Ensemble Prediction System at NCMRWF in India. Trop. Cyclone Res. Rev. https://doi.org/10.1016/j.tcrr.2020.04.003

Kensek, K.M., 2014. Building Information Modeling. Build. Inf. Model. 1-285. https://doi.org/10.4324/9781315797076

Kumar, K., Ledoux, H., Stoter, J., 2018. Dynamic 3D Visualisation of Floods: Case of the Netherlands. ISPRS - Int. Arch. Photogramm. Remote Sens. Spat. Inf. Sci. XLII-4/W10, 83-87. https://doi.org/10.5194/isprs-archives-XLII-4-W1083-2018

Li, J., Wong, D.W.S., 2010. Effects of DEM Sources on Hydrologic Applications. Comput. Environ. Urban Syst. 34, 251-261. https://doi.org/10.1016/j.compenvurbsys.2009.11. 002

Mrmwroman, 2020. Precipitation Report from 27 May to 1 June, Mrmwroman Report.

Muhadi, N.A., Abdullah, A.F., Bejo, S.K., Mahadi, M.R., Mijic, A., 2020. The Use of LiDAR-Derived DEM in Flood Applications: A Review. Remote Sens. 12, 2308. https://doi.org/10.3390/rs12142308

NCSI, 2020. Monthly Statistical Bulletin, December 2020, Monthly Statistical Bulletin. https://doi.org/10.36548/jsws.2020.2 
NCSI, 2017a. Oman National Spatial Data Infrastructure Strategy V5.0. National Center for Statistics and Information, Oman.

NCSI, 2017b. Oman National Spatial Data Infrastructure, 1st ed. National Center for Statistics and Information, Oman.

Preka, D., Doulamis, A., 2016. 3D Building Modeling in LoD2 Using the CityGML Standard. ISPRS - Int. Arch. Photogramm. Remote Sens. Spat. Inf. Sci. XLII-2/W2, 11-16. https://doi.org/10.5194/isprs-archives-XLII2-W2-11-2016

Ruíz, A.A.B., 2015. An Urban Flooding Simulation Technique by Using 3D City Information Model 3, 5467.

Siew, C., Kumar, P., 2019. CitySAC: A Query-Able CityGML Compression System. Smart Cities 2, 106-117. https://doi.org/10.3390/smartcities2010008

Soon, K.H., Tan, D., Khoo, V., Soon, K.H., Tan, D., Khoo, V., 2016. Initial Design to Develop a Cadastral System that Supports Digital Cadastre, 3D and Provenance for Singapore, in: 5th International Workshop on 3D Cadastres. pp. 419-432.

Stoter, J., Brink, L. Van Den, Vosselman, G., Goos, J., Verbree, E., Klooster, R., Berlo, L. Van, Vestjens, G., Reuvers, M., Thorn, S., 2010. A Generic Approach for 3D SDI in the Netherlands. Lect. Notes Comput. Sci. 122.

Stoter, J., Ploeger, H., Roes, R., Riet, E. Van Der, Biljecki, F., Stoter, J., Ploeger, H., Roes, R., Riet, E. Van Der, Biljecki, F., 2016. First 3D Cadastral Registration of Multi-level Ownerships Rights in the Netherlands, in: 5th International Workshop on 3D Cadastres. pp. 491504.

Stoter, J., Vosselman, G., Dahmen, C., Oude Elberink, S., Ledoux, H., 2014. CityGML Implementation Specifications for a Countrywide 3D Data Set. Photogramm. Eng. Remote Sens. 80, 1069-1077. https://doi.org/10.14358/pers.80.11.1069
Stouffs, R., Tauscher, H., Biljecki, F., 2018. Achieving Complete and Near-Lossless Conversion from IFC to CityGML. ISPRS Int. J. Geo-Information 7, 355. https://doi.org/10.3390/ijgi7090355

Tymkow, P., Karpina, M., Borkowski, A., 2016. 3D GIS for Flood Modelling in River Valleys. ISPRS - Int. Arch. Photogramm. Remote Sens. Spat. Inf. Sci. XLI-B8, 175178. https://doi.org/10.5194/isprsarchives-XLI-B8$175-2016$

UNDP, 2004. Bureau for Crisis Prevention and Recovery (Bcpr) 2004 Report : Thematic Trust Fund for Crisis Prevention and Recovery United Nations Development Programme. Bur. Cris. Prev. Recover.

Yao, Z., Nagel, C., Kunde, F., Hudra, G., Willkomm, P., Donaubauer, A., Adolphi, T., Kolbe, T.H., 2018. 3DCityDB - a 3D Geodatabase Solution for the Management, Analysis, and Visualization of Semantic 3D City Models Based on CityGML. Open Geospatial Data, Softw. Stand. 3. https://doi.org/10.1186/s40965-018-0046-7

Zerboni, A., Perego, A., Mariani, G.S., Brandolini, F., Al Kindi, M., Regattieri, E., Zanchetta, G., Borgi, F., Charpentier, V., Cremaschi, M., 2020. Geomorphology of the Gebel Qara and Coastal Plain of Salalah (Dhofar, Southern Sultanate of Oman). J. Maps 16, 187-198. https://doi.org/10.1080/17445647.2019.1708488

Zlatanova, S., Ghawana, T., Kaur, A., Neuvel, J.M.M., 2014. Integrated Flood Disaster Management and Spatial Information: Case Studies of Netherlands and India. ISPRS - Int. Arch. Photogramm. Remote Sens. Spat. Inf. Sci. XL-8, 147-154. https://doi.org/10.5194/isprsarchives-XL-8-1472014 